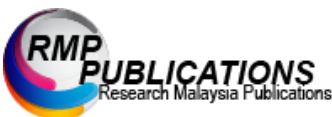

Journal of Engineering and Science Research 2 (2): 01-08, 2018

e-ISSN: 2289-7127

(C) RMP Publications, 2018

DOI: $10.26666 /$ rmp.jesr.2018.2.1

\title{
Corrosion Behaviour of Al-Si Cast Alloy Reinforced with Titanium diboride $\left(\mathrm{TiB}_{2}\right)$ and Scandium (Sc)
}

\author{
R.E., Ibrahim ${ }^{1}$, R.Rosmamuhamadani ${ }^{1}$, M.K. Talari ${ }^{1}$, Sabrina, M. Yahaya ${ }^{1}$, S.Sulaiman ${ }^{2}$ and M.I.S \\ Ismail $^{2}$ \\ ${ }^{1}$ Materials Technology Programme, Faculty of Applied Sciences, Universiti Teknologi MARA, 40450 Shah \\ Alam, Selangor, Malaysia \\ ${ }^{2}$ Mechanical and Manufacturing Department, Faculty of Engineering, Universiti Putra Malaysia, 43400 \\ Serdang, Selangor, Malaysia
}

\begin{abstract}
The aluminium-silicon (Al-Si) based on Metal Matrix Composites (MMCs) is widely used in lightweight constructions and transport applications requiring a combination of high strength and ductility. A grain refinement plays a crucial role in improving characteristics and properties of $\mathrm{Al}$ alloys. In this investigation, titanium diboride $\left(\mathrm{TiB}_{2}\right)$ and scandium $(\mathrm{Sc})$ inoculants were added to the $\mathrm{Al}-\mathrm{Si}$ alloys for grain refinement of an alloy. In this investigation, the corrosion resistance rate of $\mathrm{Al}-\mathrm{Si}$ cast alloy reinforced by $\mathrm{TiB}_{2}$ and $\mathrm{Sc}$ were measured by potentiostat (AUTOLAB) instrument. The aim of this research is to investigate the corrosion rate for $\mathrm{Al}-\mathrm{Si}-\mathrm{TiB}_{2}-\mathrm{Sc}$ composites that immersed in different concentration of acidic solutions. Besides, the immersion time of acidic solutions also was investigated. All the samples were prepared accordingly for ASTM standard by the composition of $6.0 \mathrm{wt} \% \mathrm{TiB}_{2}$ and $0.6 \mathrm{wt} \% \mathrm{Sc}$. All the samples undergo cold mounting technique for easy handling on corrosion tests. Then the samples were immersed in two different concentrations acidic medium solutions, which were 0.1 and $1.0 \mathrm{M}$ hydrochloric acids $(\mathrm{HCl})$. The corrosion rate also was investigated for immersion samples of $1.0 \mathrm{M} \mathrm{HCl}$ for 21 days. From the results obtained, added $\mathrm{TiB}_{2}$ and $\mathrm{Sc}$ onto $\mathrm{Al}-\mathrm{Si}$ alloy gave the better properties in corrosion resistance. Corrosion rates to reduce when the samples were immersed in a lower concentration of acidic medium, $0.1 \mathrm{HCl}$. However, there are some significant on the result but it still following the corrosion rates trend. Thus, improvements to reinforcement content need to be done in further research to cover the lack of this corrosion rates trend.
\end{abstract}

Key words: Al-Si alloy,metal matrix composites, titanium diboride, scandium, corrosion rate

\section{INTRODUCTION}

Aluminum alloys have been tremendous applicable in automobile and aerospace industries. It has variety superior properties such as high specific strength, chemically inert and good performances at low temperature. This types MMCs however, it has the main weaknesses which are low resistance to wear [1]. Miscellaneously of aluminum alloys have been fabricated to create the desired properties while adding the variety of reinforcement including ceramic and organic compound. The recent generation of aluminum alloys is known as aluminum hybrid composites (AMCs). The performances of these materials depending on the selecting foreign compound as it reinforced particles [2].
Aluminium matrix composites (AMCs) are used in various application due to their good physical and mechanical properties. The addition of reinforcements into a metallic matrix to improves the stiffness, specific strength, wear, creep and fatigue properties [3]. One of the main reasons for using MMCs is the addition of the reinforcement on MMCs corrosion resistance. That is important in aluminium alloy based composites where the protective oxide film imparts corrosion resistance. The corrosion resistance of aluminium and $\mathrm{Al}$ alloys can be attributed to natural protective oxide layer that forms on the surface. Accelerated MMCs corrosion starts from electrochemical and chemical interaction [4].

According to Terence, [5], corrosion is a breakdown of metal due to reactions within its area. It is the loss of water and air molecules. Corrosion also

Corresponding Author: R.Rosmamuhamadani, Universiti Teknologi MARA, 40450 Shah Alam, Selangor, +603-55444543 
occurs when an acidic or basic material touches another material. The addition of the reinforcing fibers and particles can cause accelerated corrosion of metal matrix compared to corrosion of unreinforced matrix alloy.

Ibrahim et al. [6] had studied morphology and mechanical properties of $\mathrm{Al}-\mathrm{Si}$ reinforced with different $\mathrm{TiB}_{2}$ contents. It showed that the eutectic silicon microstructure in Al-Si alloy changed from needles-look or acicular to fine grain size or globular when the added of $\mathrm{TiB}_{2}$. The mechanical studies showed that the ductility of Al-Si alloy was much lower in the absence of grain refiner, $\mathrm{TiB}_{2}$. The tensile strength of unrefined Al-Si and Al-Si with 6 wt.\%TiB2 as grain refinement were recorded 275 and $312 \mathrm{MPa}$ respectively. The hardness value for the unrefined Al$\mathrm{Si}$ alloy also shows less compared with Al-Si with grain refiner, 6 wt. $\% \mathrm{TiB}_{2}$, which are 74 and $78 \mathrm{MPa}$. This showed the results were significant improvements in mechanical properties have been obtained with the use of $\mathrm{TiB}_{2}$ as grain refiner to Al-Si alloy.

The addition of $\mathrm{TiB}_{2}$ will increase the hardness of Al-based alloy. The increase in hardness will decrease the TiB2 particle grain size. When $\mathrm{TiB}_{2}$ content is added to an alloy, the corrosion potential and corrosion current are decreased. Therefore the addition of $\mathrm{TiB}_{2}$ has positive factors to the corrosion resistance in Al. This behavior leads to positive factors of $\mathrm{TiB}_{2}$ addition on the grain size refinement [6].

Rosmamuhamadani et. al. [7] used GamryElectrode Potentiometer for measuring the corrosion rate of $\mathrm{Al}-\mathrm{Cu}$ alloys. From their experiment, anodic and cathodic polarization curves were plotted with the presence of the reference sample and $\mathrm{Al}-\mathrm{Cu}$ alloys in $0.1 \mathrm{M} \mathrm{HCl}$ solution in current density range from 2 to 6 $\mathrm{mA} / \mathrm{cm} 2$. The result from anodic and cathodic polarization curves shows that corrosion potential decreases with increasing the $\mathrm{TiB}_{2}$ content in the alloys. While the corrosion current decreased when increasing the $\mathrm{TiB}_{2}$ content. The advantage of the Linear Polarization Technique (LPR) is that the measurement of corrosion rate is made instantaneously. But LPR can only be successfully performed in relatively clean aqueous electrolytic environments. LPR will not work in gases or water where contaminate of the electrodes will prevent measurements being made.

The corrosion properties of $\mathrm{Al}-\mathrm{Cu}$ cast alloy reinforced with $\mathrm{TiB}_{2}$ by salts spray fog test also was studied [8]. The samples were exposed to the salt environment for the duration of 1 month in cabinet test in $5 \% \mathrm{NaCl}$ solutions. The results obtained Al-6 wt. $\% \mathrm{Cu}$ alloy with $3 \mathrm{wt} . \% \mathrm{TiB}_{2}$ gave the lowest value in weight loss compared to Al-6 wt.\%Cu with 6 wt $\% . \mathrm{TiB}_{2}$ and as cast Al-6 wt. $\% \mathrm{Cu}$ alloy. Al-6 wt. $\% \mathrm{Cu}$ alloy with 3 wt. $\% \mathrm{TiB}_{2}$ exhibited high corrosion resistant, resulting from its ability to form naturally corrosion oxide film on the surface, and the corrosion resistance improved due to stable oxide layer formation due to the behavior of the surface during corrosion test. From the data obtained, they found that is a variation of the corrosion rates with different $\mathrm{TiB}_{2}$ particles contents. The result shows that Al-6 wt.\%Cu with 3 wt. $\% \mathrm{TiB}_{2}$ exhibit the good corrosion property of alloy compared than other compositions in Al-6 wt.\% $\mathrm{Cu}$ alloy. The corrosion rate gave the lowest value for Al-6 wt. $\% \mathrm{Cu}$ with $6 \mathrm{wt} \% \mathrm{TiB}_{2}$ composite following Al-6 wt. $\% \mathrm{Cu}$ alloy in $5 \% \mathrm{NaCl}$ solutions. By increasing the $\mathrm{TiB}_{2}$ contents particles to Al- 6 wt. $\% \mathrm{Cu}$ alloy, the results show that the corrosion rates decreased proportionally especially for the composition of 3 wt. $\% \mathrm{TiB}_{2}$ content within 720 hours [8].

Abdel Rehim et. [9] investigated the $\mathrm{Cu}$ addition on the mechanical properties and corrosion resistance of commercially pure Al. Three different Al$\mathrm{Cu}$ alloys of 3, 6 and 9 wt.\% $\mathrm{Cu}$ content was prepared and experimentally tested both mechanically and chemically. The results show the addition of $\mathrm{Cu}$ resulted in a linear increase of the hardness, and substantial reduction in the grain size, slight reduction the impact energy, a substantial increase in the flow stress at 0.2 strains, and improve in the mechanical properties. The potentiostatic measurements showed that the susceptibility of the samples towards corrosion decreases in the order: $\mathrm{Al}>\mathrm{Al}-3 \mathrm{wt} \% \mathrm{Cu}>\mathrm{Al}-9$ wt $\%$ $\mathrm{Cu}>\mathrm{Al}-6 \mathrm{wt} \% \mathrm{Cu}$. The corrosion rates of the 3, 6 and 9 $\mathrm{wt} \% \mathrm{Cu}$ alloys in $\mathrm{HCl}$ were found to be $0.29,0.13$ and $0.21 \mathrm{~nm} / \mathrm{s}$, respectively. The different properties, i.e. impact energy, flow stress at 0.2 strain, mechanical characteristics and corrosion resistance, showed that the 6 wt. \% $\mathrm{Cu}$ is an optimal composition.

Svobodova et. al. [10] studied the evaluation of the corrosion resistance of the Al-Si alloys alloyed with the different amount of antimony. Specifically it goes about the alloy Al-Si-7Mg 0,3 which is antimony alloyed in the concentrations $0,0,001,0,005,0,01$ a 0,05 wt. $\%$ of antimony. The experimental part describes the experimental samples which were prepared for the experiment and further they were exposed to the loading in the atmospheric conditions for a period of the 3 months. The experimental samples were evaluated macroscopically and microscopically. From the results of the macroscopic analysis is apparent that with the increasing content of the antimony it leads to increased corrosion attack of experimental samples. The microscopic analysis results are not unequivocal. The significant difference is the sample without $\mathrm{Sb}$ and alloyed $\mathrm{Sb}$. The sample without $\mathrm{Sb}$ (primary alloy) has the better corrosion resistance. 
Therefore they concluded that the antimony influence on the corrosion resistance of the AlSi7Mg0,3 alloy is rather negative. The surface treatment that the machined surface of the material has better results after the corrosion loading that the part of the material after casting. It has been influenced by the presence of the interdendritic porosity in the research of corrosion resistance of the $\mathrm{AlSi} 7 \mathrm{Mg} 0,3$ alloys as documents the microscopic analysis. For the further research in this area, they also recommended using use higher differences of wt. \% for the alloy Al-Si alloys with antimony (for example $0 ; 0,005 ; 0,05 ; 0,1$ and $0,2 \mathrm{hm}$. $\% \mathrm{Sb})$. The results of the antimony influence on the corrosion resistance of the $\mathrm{Al}-\mathrm{Si}$ alloys would be probably clearer.

Polarization is said to be either anodic or cathodic for displacement of an electrode potential from its equilibrium value. Anodic polarization caused by a slow anodic reaction called oxidation while cathodic polarization caused by a slow cathodic reduction. Corrosion of $\mathrm{Al}-\mathrm{Si}, \mathrm{Al}-\mathrm{Si} / \mathrm{TiB}_{2}$ and $\mathrm{Al}-$ $\mathrm{Si} / \mathrm{TiB}_{2} / \mathrm{Sc}$ in two different concentrations of $\mathrm{HCl}$ was studied. To measure corrosion rates, the method must follow its standards requirement and procedure.

\section{EXPERIMENTS}

\section{Composite Fabrication}

Firstly, Al-7wt $\% \mathrm{Si}$ was melted at $780^{\circ} \mathrm{C}$ in an induction furnace. After that two types of reinforcement were added to the molten $\mathrm{Al}-7 \mathrm{wt} \% \mathrm{Si}$ in the atomic ratio in accordance with $\mathrm{TiB}_{2}$ and $\mathrm{Sc}$ by stirring method. The stirrer that uses in the stirring method is mild steel stirrer that was coated with zirconia. To avoid contamination of the molten metal with iron, the latter coating was applied to the mild steel stirrer. The steps are repeated to reinforced the alloy with other composition, $0.6 \mathrm{wt} . \%$ and $\mathrm{TiB}_{2}$ and $0.6 \%$ wt Sc.

Permanent mold made of stainless steel was involved in a casting process. Permanent mold casting is commonly used to produce complex parts. Permanent mold casting also is preferred because it produced in tight dimensional tolerances with high surface quality. The permanent mold casting that user is able to produce three samples at one pouring.

An electrical furnace that heat is applied by induction heating of metal known as induction furnace. The advantages of the induction furnace are clean, energy-efficient and well-controllable melting process. The induction furnace is more efficient than other means of metal melting. The furnace is a channel type induction furnace and contains shell lined with refractory material. Feed material, an alloy containing ore and carbon reluctance that charged through a hole at the side of the furnace. The material then was heated by combustion of different gases that formed after heated the carbon reluctance and ore mixture under certain conditions and additional fuel combustion. The temperature controller was used to monitor the furnace temperature was maintained at $700-780{ }^{\circ} \mathrm{C}$. Then molten metal was poured into the mold cavity and leave it cool down for a few minutes. The metal was removed after 20 minutes holding time.

\section{Sample preparation}

The samples $\mathrm{Al}-\mathrm{Si}, \mathrm{Al}-\mathrm{Si} / \mathrm{TiB}_{2}$, and $\mathrm{Al}-\mathrm{Si} / \mathrm{TiB}_{2} / \mathrm{Sc}$ alloy were cut by using the linear precision saw (Buehler IsoMet@5000). The speed used is 500 rpm. The sizes of the samples were $4 \mathrm{~cm}^{2}$. Then the nichrome wire that was inserted into glass tubing rod were soldered to the samples. The wire content of the soldering method was $\mathrm{Sn}$ and $\mathrm{Pb}$ with ratio 60:40. The soldering technique was careful handled to attach the nichrome wire to the sample. Figure 1 and 2 shows the glass tubing rod with nichrome wire and soldering the nichrome wire to the sample.

Cold mounting was used to cast the sample. The process required are mixing the epoxy and hardener with a ratio of 10:1. The mixture was poured into a mold for 24 hours. It formed a solid sample and makes it easy to handle during grinding and polishing process. Figure 3 shows the cold mounting sample made up from mixed of epoxy and hardener.

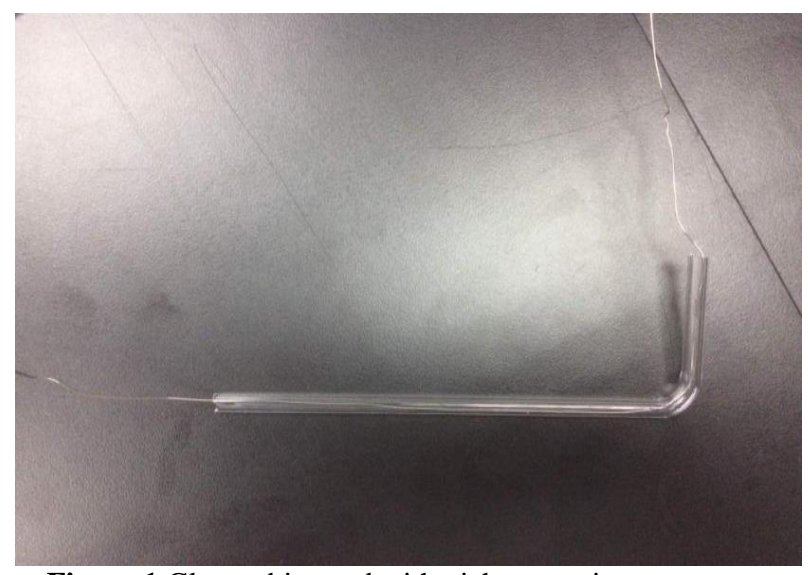

Figure 1 Glass tubing rod with nichrome wire 


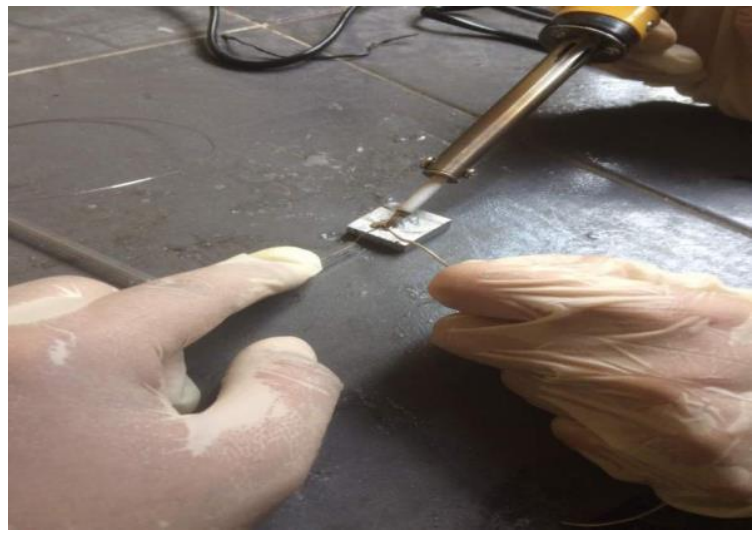

Figure 2 Soldering the nichrome wire to the sample

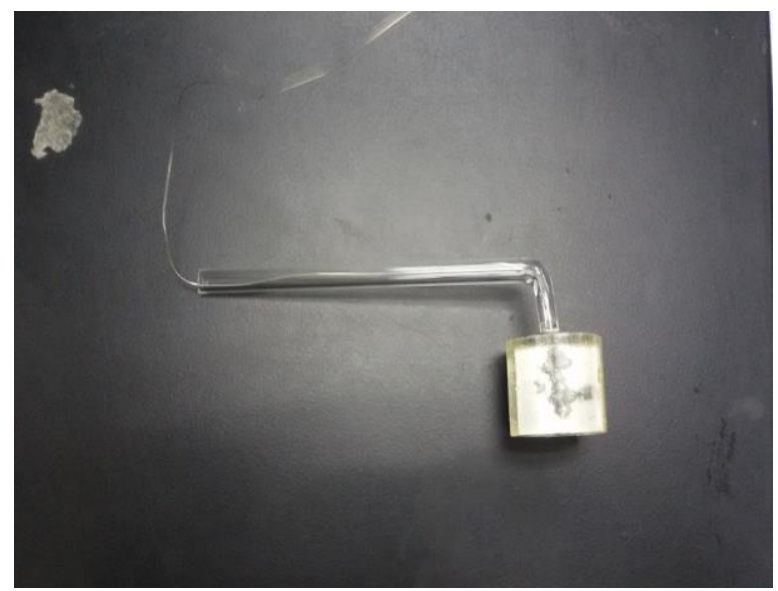

Figure 3 Cold mounting sample

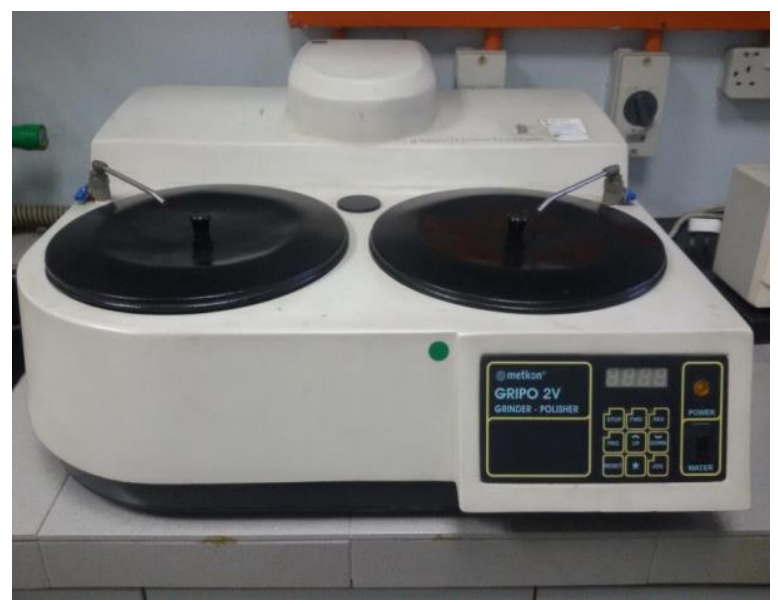

Figure 4 Grinding and polishing machine

The samples surface were ground with sandpaper with starting grit of 120 then followed by $320,600,800$ and 1000. The sandpaper that has a small number of grit shows that abrasive paper is roughness while a large number of grit shows the fine roughness. The function of sandpaper grind is to ensure that the surfaces of samples are clean, flat and smooth. Then the sample was polished using the polishing cloth and
$1 \mu \mathrm{m}$ silica paste. Figure 4 , shows the grinding and polishing machine, while Figure 5 shows the alloy specimen mounted in a mould.

\section{Corrosion testing}

Corrosion test was carried out on each alloy in the ascast conditions. Potentiostatic polarization measurements were carried out using a Radiometer Analytical model PGZ 100 Potentiostat/Galvanostat with VoltaLab software. The working electrodes employed were the graphite and Al-Cu bars. Anodic and cathodic polarization curves were plotted. Figure 6 below shows the Potentiostat (AUTOLAB) machine used for corrosion test

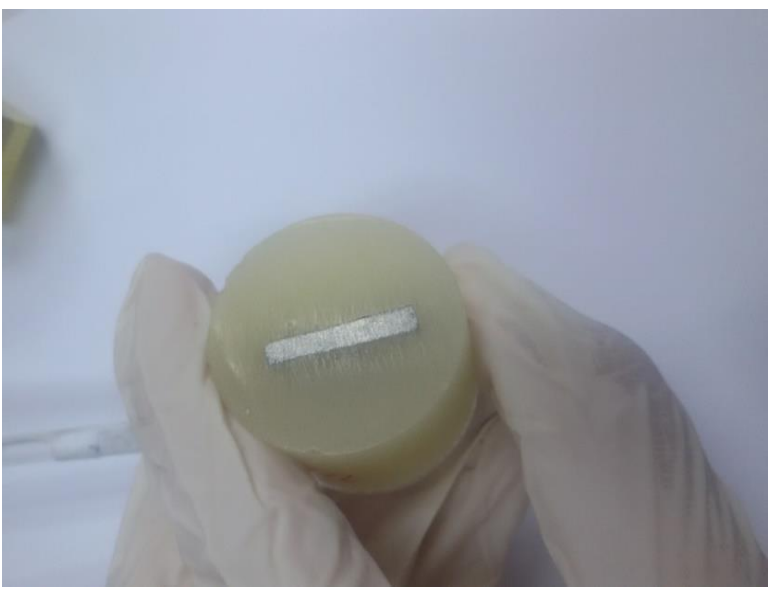

Figure 5 Sample surface for corrosion test

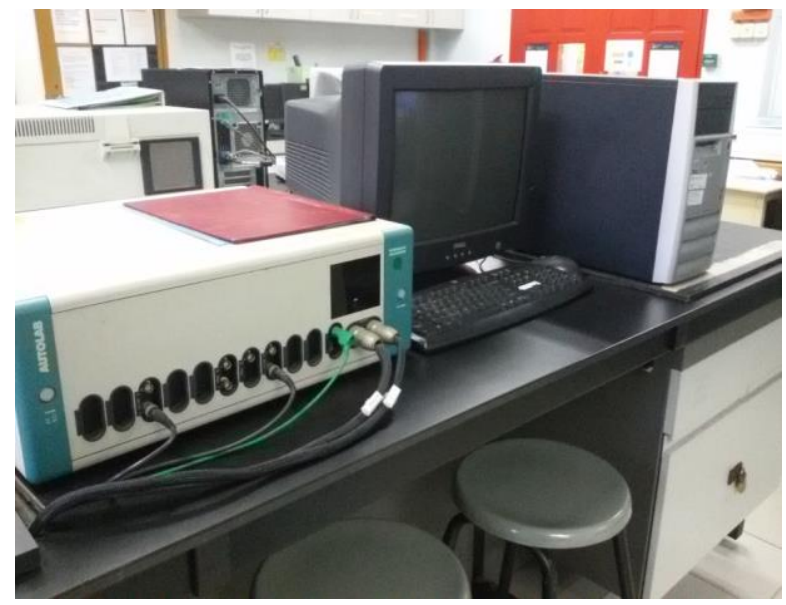

Figure 6 Potentiostat (AUTOLAB) for corrosion test

The investigated electrodes were cut as cylindrical rods, welded with $\mathrm{Cu}$-wire for electrical connection to contact the test solution. The experiments were performed in a $250 \mathrm{ml}$ volume Pyrex glass cell using $\mathrm{Pt}$ wire and a saturated calomel electrode as auxiliary and reference electrodes, respectively. All potentials given in this research are referred to this reference electrode. The experiments 
were carried out in 0.1 and $1.0 \mathrm{M} \mathrm{HCl}$ solution. The $\mathrm{HCl}$ solution was freshly prepared from analytical grade using doubly distilled water. For each run, a freshly prepared solution as well as a cleaned set of electrodes was used.

Besides, the test also was carried out in immersed the specimens in $1.0 \mathrm{HCl}$ within 21 days. The data were taken for every week to determine the corrosion rate of $\mathrm{Al}-\mathrm{Si}-\mathrm{TiB} 2-\mathrm{Sc}$ composites. The experiment was performed in a $250 \mathrm{ml}$ volume of beaker using nichrome wire and titanium as auxiliary and $\mathrm{Ag} / \mathrm{AgCl}$ as reference electrodes. The set-up is shown as in figure 7.

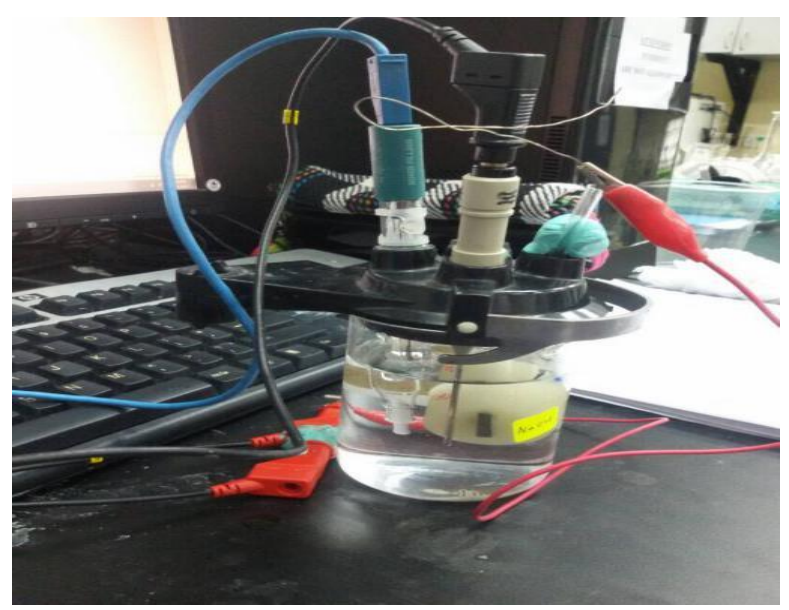

Figure 7 The set-up connection to the data reader

\section{RESULTS AND DISCUSSION}

Corrosion rate was measured by Polarization Resistance (LPR) method. This method potentiostat AUTOLAB instrument was used to obtain the data needed. There is corrosion potential (Ecorr), corrosion current (Icorr) and corrosion rates. Based on Table 1, it was found that corrosion potential (Ecorr) and corrosion rates $(\mathrm{CR})$ is decreasing when all the reinforcement mixed with $\mathrm{Al}-\mathrm{Si}$ cast alloy.

Nevertheless, there was some increment of corrosion rate at $\mathrm{Sc}$ reinforcement. The best corrosion resistance was present when the Al-Si reinforced with TiB2 and Sc. While, the Table 2 showed that the reinforced metal matrix with $\mathrm{TiB}_{2}$ gives the higher value of corrosion rates when immersed in a higher concentration of $\mathrm{HCl}$ solution. The amounts of corrosion rate are $53.36 \mathrm{~mm} /$ year. The corrosion current and corrosion rates showed the minimal value when all the reinforcement mixed together with Al-Si metal matrix. The amount of corrosion rate was $5.0 \mathrm{x}$ $10^{-4} \mathrm{~mm} /$ year.

The addition of Sc can improve the ductility, fracture, impact properties and formation into grain refinement that help to reduces corrosion rate. The small amount of Sc was good enough to modify the Al$\mathrm{Si}$ properties. In this research, the Sc content used was $0.5 \mathrm{wt} \%$ and it's good enough to reduce the corrosion rates. The reason was proved by the percent decrement of corrosion rate that was $98.9 \%$ with the minimal amount of corrosion rate.

Table 1 Electrochemical parameters for Al-Si reinforcement immersed in $0.1 \mathrm{M}$

\begin{tabular}{lccc}
\hline Reinforcement & Ecorr & Icorr & CR (mm/year) \\
\hline Al-Si & -635.25 & $17.4 \times 10^{-6}$ & 0.58 \\
Al-Si-TiB $_{2}$ & -644.92 & $2.53 \times 10^{-6}$ & 0.16 \\
Al-Si-TiB $_{2}$-Sc & -246.63 & $5.56 \times 10^{-9}$ & $3.13 \times 10^{-4}$
\end{tabular}

Table 2 Electrochemical parameters for Al-Si reinforcement immersed in $1 \mathrm{M} \mathrm{HCl}$ solution

\begin{tabular}{lccc}
\hline Reinforcement & Ecorr & Icorr & \multicolumn{2}{c}{ CR (mm/year) } \\
\hline Al-Si & -727.91 & $73.26 \times 10^{-6}$ & 2.34 \\
Al-Si-TiB & -155.72 & $10.01 \times 10^{-6}$ & 0.56 \\
Al-Si-TiB $_{2}$-Sc & -506.04 & $9.46 \times 10^{-9}$ & $5.0 \times 10^{-4}$
\end{tabular}

The bar chart in Figure 8 showed the variation of corrosion rates values when the sample immersed in $0.1 \mathrm{M} \mathrm{HCl}$ acid solution. Summarize it as a whole, it showed that corrosion rates were reduced when all the reinforcement of $\mathrm{TiB}_{2}$ and $\mathrm{Sc}$ was mixed together with Al-Si metal matrix. Based on this bar chart, it can be clearly seen that the reinforcement with Sc is not significant in value. The corrosion rate continues to reduce when metal matrix mixed with $\mathrm{Sc}$. The trend of corrosion rates was proved that $\mathrm{Sc}$ can reduce the corrosion rates.

While Figure 9 showed that the corrosion rates when sample immersed in a higher concentration of $\mathrm{HCl}$ acid solution. The corrosion rates showed that there was an increased value than corrosion rates values in immersion into a lower concentration of $\mathrm{HCl}$ acid solution. The bar chart showed the reinforcement of metal matrix with $\mathrm{TiB}_{2}$ gives significant value. Nevertheless, the corrosion resistance is good when all the reinforcements are mixed together 


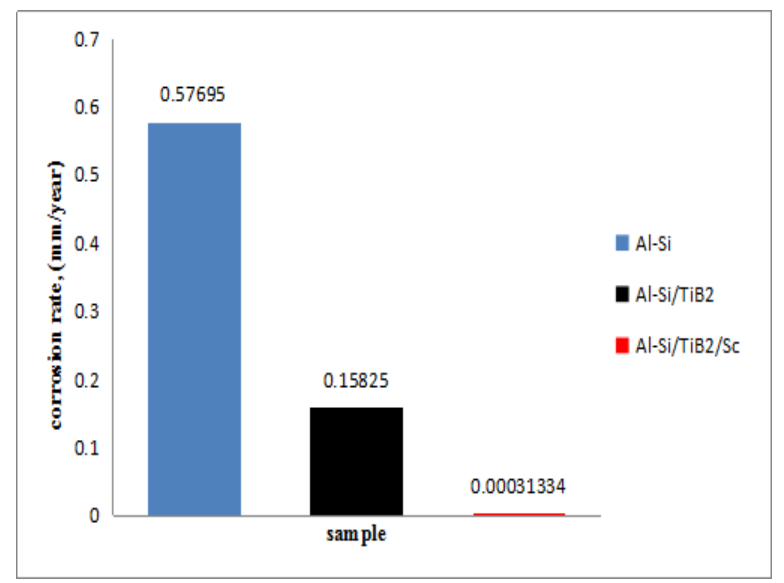

Figure 8 Corrosion rates in $0.1 \mathrm{M} \mathrm{HCl}$ acid solution

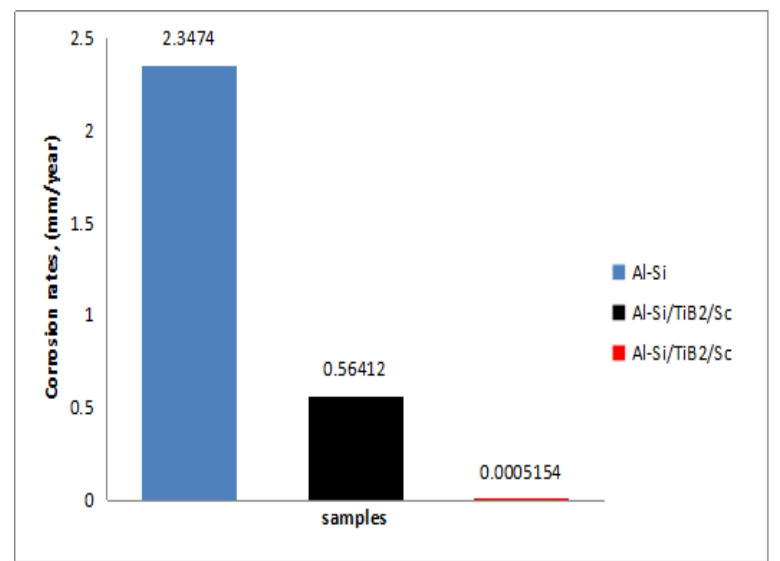

Figure 9 Corrosion rates in $1.0 \mathrm{M} \mathrm{HCl}$ acid solution

Figure 10 shows typical polarization curves for Al-Si reinforcement in chloride media. It shows the anodic polarization curve of Al-Si reinforcement. The curves showed a monotonic increase of current with potential until the current reached the maximum value. After this maximum current density value, the current density declined rapidly with potential increased. As the result obtained, $\mathrm{Sc}$ gaves smallest value of corrosion rates, $3.13 \times 10^{-4} \mathrm{~mm} /$ year. Icorr value obtained also the smallest value, $5.55780 \mathrm{nA}$. Reinforcement with $\mathrm{TiB}_{2}$ also gives better corrosion resistance and polarization curve shows the decreasing in Icorr value that was $2.526 \mu \mathrm{A}$.

Figure 11 showed the polarization curve of sample when immersed in higher concentration of $\mathrm{HCl}$ solution. From the curve obtained, it is suggested that Sc curve gives better corrosion resistance when the polarization curve shows the minimal value of Icorr. However the corrosion rates are higher than the corrosion rates of $\mathrm{Sc}$ that immersed in lower concentration of $\mathrm{HCl}$ solution. The value obtained was $5.15 \times 10^{-4} \mathrm{~mm} /$ year that smallest value obtained from other reinforcement and Icorr value obtained is 9.46210nA.

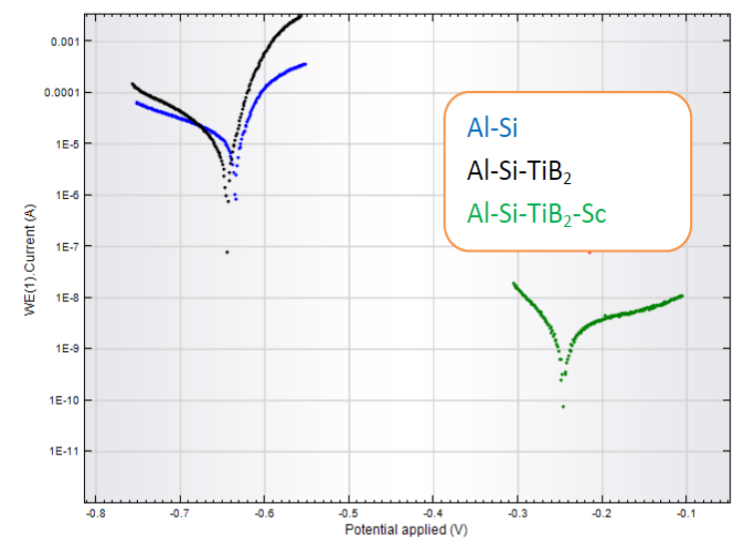

Figure 10 Polarization curve of samples immersed in $0.1 \mathrm{M}$ $\mathrm{HCl}$ acid solution

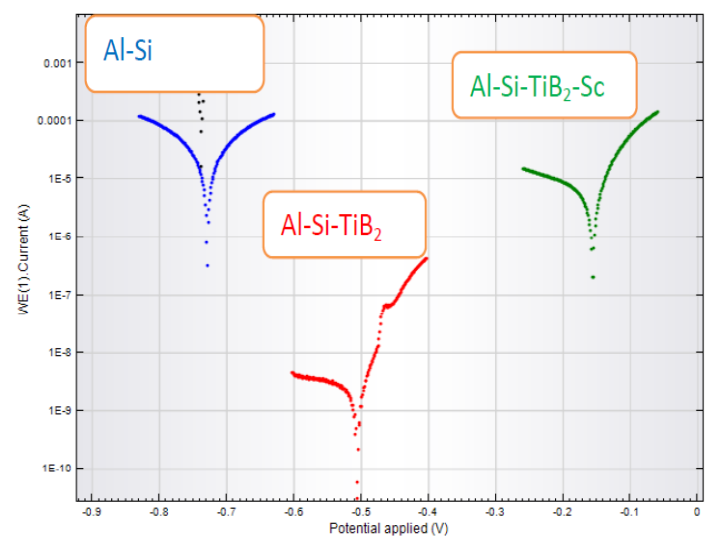

Figure 11 Polarization curve of samples immersed in 1.0 $\mathrm{M} \mathrm{HCl}$ acid solution

\section{Effect of immersion time}

$\mathrm{Al}-\mathrm{Si}$ without any reinforcement shows the highest corrosion rate compared to the others which was 1027.8 (mm/year). In addition to another compound which is $\mathrm{TiB}_{2}$, the corrosion rate showed slightly reduced for $7.7 \%$ compared to $\mathrm{Al}-\mathrm{Si}$ cast alloy. Table 3 shows the summarized of corrosion rate when $\mathrm{Al}-\mathrm{Si}$ cast alloy was reinforced by $\mathrm{TiB}_{2}$ and $\mathrm{Sc}$. It showed a corresponding result to the previous research and was supported by Kumar et, al. [11]. They stated the corrosion rate of aluminium based MMCs increase with increasing in $\mathrm{TiB}_{2}$ content in the cast and forged. $\mathrm{Al}-\mathrm{Si}-\mathrm{TiB}_{2}-\mathrm{Sc}$ composite shows the lowest in corrosion rate which was 0.00379 . In short, the corrosion rate increased directly proportional to the addition of reinforcements used.

Table 3 Corrosion rate of Al-Si cast alloy and their composites immersed in $1.0 \mathrm{HCl}$ for 21 days 


\begin{tabular}{cccc}
\hline Type of alloys & $1^{\text {st }}$ week & $2^{\text {nd }}$ week & $3^{\text {rd }}$ week \\
\hline Al-Si & 1027.8 & 590.9 & 391.5 \\
Al-Si-TiB 2 & 862.7 & 411.5 & 495.5 \\
Al-Si-TiB 2 -Sc & 0.0038 & 0.0041 & 0.0068 \\
\hline
\end{tabular}

For the immersion in 14 days ( $2^{\text {nd }}$ week), there were a presence certain uncertainties results that affected the corrosion rate of the alloys. Referring to Table 3, the value of corrosion rate of $\mathrm{Al}-\mathrm{Si}$ shows dramatically increased to $590.97 \mathrm{~mm} /$ year compared to the 7 days. However, it shows that $\mathrm{Al}-\mathrm{Si}_{-}-\mathrm{TiB}_{2}-\mathrm{Sc}$ composite possessed excellent in corrosion resistance than others. The result of $\mathrm{Al}-\mathrm{Si}$-TiB2-Sc composite quite excellent which is $0.0040 \mathrm{~mm} / \mathrm{year}$ and gave $59 \%$ better than Al-Si cast alloy itself. Conventionally, the addition of scandium element might enhance the physical characteristic such as strength refine grains and inhibit recrystallization [12].

For the days of 21 ( $3^{\text {rd }}$ week) immersed in $\mathrm{HCl}$, the corrosion rate was $3915 \mathrm{~mm} /$ year for $\mathrm{Al}-\mathrm{Si}$ cast alloy, while for $\mathrm{Al}-\mathrm{Si}-\mathrm{TiB}_{2}$, and $\mathrm{Al}-\mathrm{Si}_{-} \mathrm{TiB}_{2}-\mathrm{Sc}$ composites, the value were 0.0068 and 0.0036 respectively. From the days $7, \mathrm{Sc}$ element made the composite having a high value in corrosion resistance. However, the trend in corrosion rate of these alloys was very slowly when increased by exposure time. Figure 12 shows the corrosion rate was obtained from Autolab-potentiostat for 21 days) and were summarized in the histogram. Based the corrosion potential, the rate for hydrogen to evolve is equal to the rate of metal dissolution and expressed as current density displayed in the anodic-cathodic graph in figure 13.

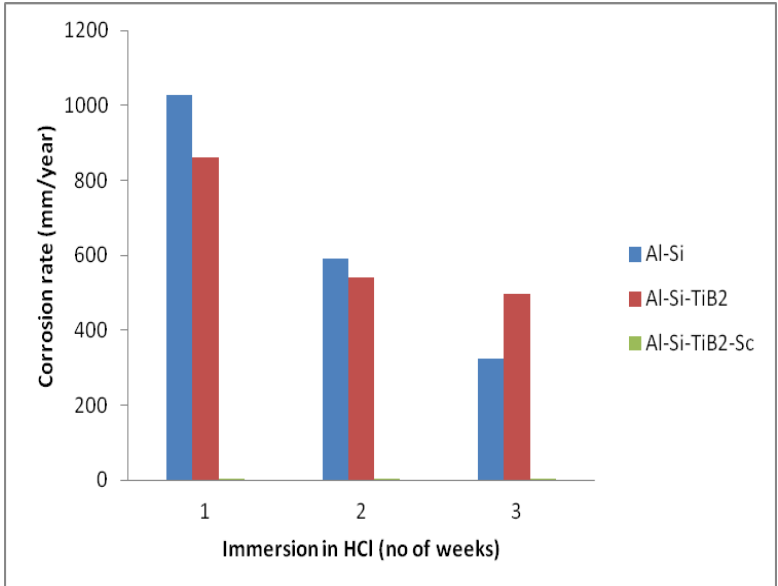

Figure 12 The corrosion rate of Al-Si cast alloy and their composites from Autolab-potentiostat for 21 days

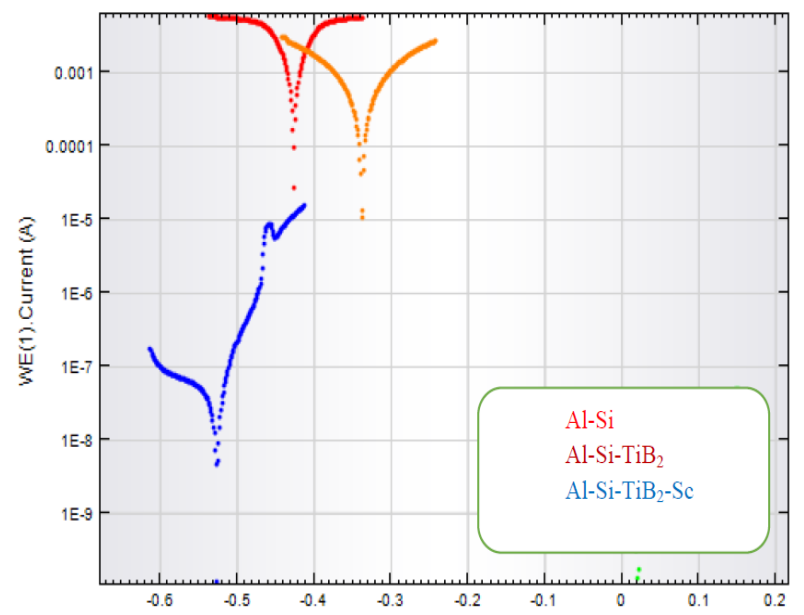

Figure 13 The relationship between current (A) and potential applied $(\mathrm{V})$ on different samples of alloy.

\section{CONCLUSIONS}

From the study, it can be concluded that the corrosion rates reduced when $\mathrm{TiB}_{2}$ and $\mathrm{Sc}$ were added to $\mathrm{Al}-\mathrm{Si}$ cast alloy. These content to gave better corrosion resistance when immersed in two different concentrations of $\mathrm{HCl}$ solutions. It found that the composite of $\mathrm{Al}-7 \mathrm{wt} \% \mathrm{Si}-6 \mathrm{wt} \% \mathrm{TiB}_{2}-0.6 \mathrm{wt} \% \mathrm{Sc}$ that immersed in lower concentration acid solution. $0.1 \mathrm{M}$ gave better corrosion rates. The results also show that the corrosion resistance of $\mathrm{Al}-\mathrm{Si}_{-} \mathrm{TiB}_{2}-\mathrm{Sc}$ composite gave the lower value compared to $\mathrm{Al}-\mathrm{Si}-\mathrm{TiB}_{2}$ and $\mathrm{Al}-\mathrm{Si}$ cast alloy itself. The values were lower in the days of 7 , 14 and 21 days when immersed for 21 days in $\mathrm{HCl}$ solution.

\section{ACKNOWLEDGEMENTS}

The authors would like to thank Faculty of Applied Sciences, Universiti Teknologi MARA, and Faculty of Engineering, Universiti Putra Malaysia for the facilities. This work is funded by Ministry of Higher Education (MOHE) Malaysia under Fundamental Research Grant Scheme 2015 (UPM/700-2/1FRGS/0301-15-1632FR).

\section{REFERENCES}

[1] Pramanik, A. 2016. Effects of reinforcement on wear resistance of aluminum matrix composites.Transactions of Nonferrous Metals Society of China (English Edition) 26(2), 348-358.

[2] Bodunrin, M. O., Alaneme, K. K., \& Chown, L. H. (2015). Aluminium matrix hybrid composites: A review of reinforcement philosophies; Mechanical, corrosion and tribological 
characteristics. Journal of Materials Research and Technology 4(4), 434-445.

[3] Ramnath, B.V., Elanchezhian, C., Annamalai, R.M., Aravind, S., Atreya, T.S.A., Vignesh, V.,\& Subramanian, C. 2014. Aluminium Metal Matrix Composites- A Review. Review Advance Material Science 38, 55-80.

[4] Hihara, L.H. 2005. Corrosion of Metal-Matrix Composites in ASM Handbook. Corrosion:Materials, S.D. Cramer and B.S Covino, Jr., Ed., ASM International, Materials Park, $O H$ 13, 526-542.

[5] Terence, B. 2016. Corrosion. The Corrosion Technology Laboratory (NASA), NACE International, 1.

[6] R.E. Ibrahim, R. Rosmamuhamadani, Ma.K. Talari, Sabrina, M. Yahaya, S. Sulaiman, M.I.S. Ismail. 2017. Preliminary Study on Properties of Aluminium-Silicon (Al-Si) Alloys Reinforced by In-Situ Titanium Diboride $\left(\mathrm{TiB}_{2}\right), \quad$ Key Engineering Materials, Vol. 737, 11-15.

[7] Rosmamuhamadani, R., Sulaiman, S., Azmah Hanim, M.A., Ismail, M.I.S., Talari, M.K., \&
Sabrina, M.Y. 2016. Corrosion Characterisation of Al-Cu Reinforced In-Situ TiB 2 . MATEC Web of Conferences 78, 1-7.

[8] Rosmamuhamadani, R. 2016. Characterization and Mechanical Properties of in-situ Titanium Diboride Reinforced Aluminium Copper Alloy Composites. Phd Thesis-Universiti Putra Malaysia

[9] Abdel Rahim. S.S, Hassan, H.H and Amin, M.A. 2002. Applied Surface Science 187, 279-290

[10]Svobodova, J. Cais, J., Weiss, V. 2016. The Evaluation of the Corrosion Resistance of the $\mathrm{Al}-\mathrm{Si}$ Alloys Antimony Alloyed 2014. Archives of Foundry Engineering 14(2), 13 - 18.

[11] Shi, Y., Pan, Q., Li, M., Huang, X., \& Li, B. 2014. Effect of $\mathrm{Sc}$ and $\mathrm{Zr}$ additions on corrosion behaviour of $\mathrm{Al}-\mathrm{Zn}-\mathrm{Mg}-\mathrm{Cu}$ alloys. Journal of Alloys and Compounds 612, 42-50.

[12] Kumar M., N.S. Kumaran, \& Kumaraswamidhas, L. A. 2015. An investigation of mechanical properties and corrosion resistance of Al2618 alloy reinforced with $\mathrm{Si}, \mathrm{AlN}$ and $\mathrm{ZrB}$ composites. Journal of Alloys and Compounds 652, 244-249. 